\title{
17 INTER-ORGANIZATIONAL KNOWLEDGE MANAGEMENT. THE IMPORTANCE OF ORGANIZATIONAL AND ENVIRONMENTAL CONTEXT
}

\author{
Josep Capó, Enrique Masiá and Francisco C. Lario \\ Universidad Politécnica de Valencia, SPAIN \\ Email: [pepcapo, emasia, fclario]@omp.upv.es
}

\begin{abstract}
This paper analyzes knowledge management in an inter-organizational level. First, a brief literature review is carried out. After, knowledge management facilitators are studied, analyzing two key factors; the organizational and the environmental context. Last point studies the particular case of SMEs, studying the importance of the cluster concept in order to improve the knowledge management process in an inter-organizational level.
\end{abstract}

\section{INTRODUCTION}

Knowledge Management is beginning to play an important role in the emerging economic paradigm. This is evidenced by the fact that it is considered to be a competitive factor in the business literature of the last decade.

There are distinct forms of understanding and classifying knowledge. The focus in the literature is principally on knowledge types: tacit, explicit, individual, organizational, etc., but there are many others factors to be taken into account.

Among them, the existing interdependence between knowledge and both organizational and environmental context stand out. This interrelation is especially important, because it is in these contexts where new knowledge is created.

Each specific context requires a different form of knowledge management, as well as distinct support systems. This becomes more evident when organizational boundaries are surpassed and knowledge management at an inter-organizational level begins.

A brief literature review about the relation between knowledge management and organizational and environmental structure will be carried out in this paper. Subsequently, the requirements that should be given in order to create and share knowledge in an inter-organizational SME context will be analyzed. These requirements focus on the necessity for new organizational forms and the 
importance of clusters in order to create a collaborative business ecosystem that makes knowledge generation and management easier.

\section{BRIEF LITERATURE REVIEW}

The majority of the existing literature about knowledge management, in the interorganizational field, focuses on the horizontal alliances between two or more associates. Few authors focus on the vertical alliances between suppliers and clients. Most of the results obtained for the horizontal type relations are perfectly applicable to the vertical type (Levina, 1999).

On the other hand, while most authors focus on those inter-organizational relationships which are specified in formal agreements, the knowledge exchange may take place in social networks which are governed by shared norms of the exchange, instead of legally binding contracts (Appleyard, 1996; Liebeskind et al., 1996).

Some papers about inter-organizational collaboration attempt to extend the resource-based view of the firm to reach outside organizational boundaries, in order to these relations are a key dimension for companies competitiveness (Liebeskind et al, 1996; Powell et al, 1996; Dyer and Singh, 1998; Powell, 1998).

These authors indicate that, besides the internal resources, the companies should keep in mind the constitution of inter-organizational nets as a source of competitive advantage. These inter-organizational relationships are especially important in industries like biotechnology, where knowledge is quickly changing, and distributed among inter-organizational nets (Grant and Badden-Fuller, 1995; Liebeskind et al., 1996; Powell et al., 1996; Powell, 1998).

From the point of view of innovation, Ding and Peters (2000) indicate that, to be able to innovate in an effective way, companies should create collaborations with other companies. Inter-organizational collaborative nets, or strategic alliances, increase the innovative capacity of the companies, because the knowledge flows are facilitated through them. These authors revise the existing literature on knowledge management, concluding that the practices in this field vary from one company to another. This facilitates knowledge flow, and, at the same time, it allows innovation, whenever these collaborative nets are appropriately created and managed.

There are other kinds of analysis regarding knowledge management at an interorganizational level such as the one carried out by Levy et al. (2001), in which the term "co-opetition" is introduced, to indicate the simultaneousness between cooperation and competition. This term lumps together the transference of knowledge that could be the key to obtain a competitive advantage for SMEs, through the use of knowledge obtained from cooperation between enterprises.

Grant (2001) indicates that, in many cases, enterprises that establish strategic alliances focus more on accessing than acquiring knowledge from its associates. This access permits an increase in the use of resources based on knowledge, which is converted to advantages for the company when there is uncertainty, for example, concerning technological changes.

Grant (2001) also indicates that there are occasions when a greater integration and diffusion of knowledge in collaboration among different companies than inside one's own company (Toyota supply chain, or networks of SMEs in the north of 
Italy, for example). This is because among the different companies some informal relationships are usually created, based on common interests and on willingness to share experiences. This turns out to be much more effective in order to integrate and to transfer knowledge than most formal processes inside a company.

Apostolou et al. (2003) talk about creating networks of knowledge in the field of the Extended Enterprise, indicating that both innovation and competitive advantage increase through the creation and exploitation of Knowledge Chains.

Besides research already mentioned, Knowledge Management papers at an interorganizational level, that focus on certain sectors, can be found; in the construction sector, Bresnen and Marshall (2000), Cushman (2001) or Egbu and Botterill (2001) can be mentioned; Apostolou et al. (1999) analyze the development and use of cooperation tools, based on the Internet, to facilitate the transmission of knowledge through distinct organizations that form part of the wood and furniture sector.

Lastly, some authors that propose models for knowledge management at an inter-organizational level can be found, such as Nonaka et al. (2000) or Ciborra and Andreu (2001). These authors start from intra-organizational knowledge management models to later study their applicability outside their own organization.

\section{KNOWLEDGE MANAGEMENT FACILITATORS PROCESSES}

In this section, the main factors that can act as facilitators in knowledge generation and exchange processes at an inter-organizational level will be analyzed. Two types of factors will be studied; organizational ones, and those that have to do with the environment in which companies work.

\subsection{Organizational factors}

Several authors describe what attributes companies should have to be successful in the new economy based on knowledge. These characteristics are especially important, since if they are not given in all the participant companies in a certain project, it will be impossible to generate, acquire, transfer and combine knowledge among them, in order to obtain the end client satisfaction.

Teece (2001) affirms that companies should be characterized as being entrepreneurial, with dynamic capacities, and organized in order to be flexible and with a high answer capacity. In short, he proposes that they should fulfill the following attributes:

- Flexible limits. They must be well predisposed to outsourcing and strategic alliances.

- High powered incentives, to encourage an aggressive response in competitive developments.

- Non-bureaucratic decisions making, decentralized and autonomous, so far as possible.

- Shallow hierarchies that facilitate quick decision making and continuous flows of information from the market towards the centers of decision.

- Innovative and entrepreneurial culture that favors quick answers and the creation of specialized knowledge. 
Nonaka et al. (2000) propose in their model an interactive knowledge creation spiral, in both intra and inter-organizational levels. For that, the authors indicate the necessity of a leadership that facilitates the knowledge creation process. In the interorganizational case these leadership must be done by the person responsible for each project of each one of the participant companies.

According to these authors, a transfer process takes place through the limits of the organizations, so that the knowledge of each one interacts, generating new knowledge. Through this dynamic interaction, knowledge created by the organization can give an impulse to the mobilization of knowledge possessed by the external organizations, as consumers, external companies, distributors, etc. For example, a change in the productive process of a company can imply changes in the processes of its suppliers, and they can suppose a new cycle of processes and product innovation in the company.

Lastly, Ciborra and Andreu (2001) indicate that interconnection among different companies does not happen in an immediate fashion, but rather there must be a series of conditions, with regards to the infrastructures of the companies, to the compatibility of resources and of data systems. The fact that the companies have, for example, incompatible ERP systems can block the whole relationship between these companies.

Given these factors and the fact that Knowledge Management is a tool that helps one to become more competitive, in an unstable and ever-changing environment, it is deduced that an organizational structure that eliminates barriers is necessary to the creation, transfer and diffusion of knowledge in an inter-organizational level.

If one considers each business opportunity, concepts related with Virtual Organizations will help us to define the requirements for knowledge management at this level.

\subsection{Environmental factors}

In the previous section, the importance of the environment and of the organizational context for knowledge creation and transmission at an inter-organizational level has been analyzed. In short, the importance of creating new virtual organizational forms, by means of which this process is facilitated, has been studied.

These virtual organizations are characterized, mainly, for their fast configuration every time that a market opportunity is presented, thanks to open systems structures and to the use of ICT.

This need for a fast configuration implies that information and knowledge should flow horizontally through the network nodes. All the potential participants in the VO should have access to information and knowledge, to be able to take decisions.

In order for this configuration to take place, the existence of an environment which guarantees a series of factors that allows for this configuration and knowledge management among the participant companies becomes necessary. This environment should constitute a true business ecosystem that guarantees the following points (Camarinha-Matos, 2002):

- Trust building

- Common interoperability, ontology and distributed collaboration infrastructures

- Agreed business practices

- Sense of community 
- Sense of stability

This is especially important in the case of SMEs since, because of their characteristics (lack of resources, lack of defined managerial strategies), they have difficulties in thinking about innovation and knowledge management.

In this particular case, the fact that the companies are located in a certain territory can favor greater product specialization, greater flexibility and a considerable increase in competitiveness. The grouping in function of a group of abilities, knowledge, technologies or markets, can be a catalyst that impels the innovative process in companies. In this case, the existing implicit knowledge in a territory plays a vital role, by means of the establishment of mechanisms of collaboration and participation, formal or informal, of the different public and private agents of the territory.

In the following section, one of these factors will be analyzed, focusing on the case of industrial clusters.

\section{THE PARTICULAR CASE OF SMES}

Recent theories on endogenous growth point to knowledge generation and technological innovation as the true drivers of local (or regional) strategic change. These factors, as opposed to the simple accumulation of capitals, conclude in the innovation of products and processes.

Various authors have made similar propositions from different fields: Sabel (1992); Porter (1994); Sweeney (1987), Pyke and Sengenberger (1990), Benko and Lipietz (1994), Becattini (1989), Bagnasco, (1977), Brusco (1982), Cagmani (1992).

Therefore, the competitive advantage of the economies and firms seems to reside mainly in their innovation capacity. This corresponds to "know-how" which is, in fact, one of the aspects of the tacit knowledge. It should be considered also that both knowledge dimensions could be effective only if they are supplemented with other factors linked with economic development: physical, social, and organizational assets.

If we keep in mind, as Scott (1989) points out that "the quality of life of the inhabitants of a territory come, ultimately, from the competitiveness of the firms located there, that is to say, of the capacity of those to produce and sell their products and services to the world, with positive economic results in a sustained way", it seems that the measures implemented to develop knowledge management and generation of the firms located in a territory and concentrated around a cluster would contribute to the improvement of the quality of life of the citizens.

In the European case, the preponderance of SMEs in the economy represents a barrier to the transition from the traditional economies to those based on knowledge. In this sense, it should not be forgotten that the limited resources of the SMEs do not favor their managers or owners in dealing with the processes of strategic change, absolutely necessary in the current scenarios of the new global economy.

This circumstance is also reflected in the management patterns followed by most SMEs that tend to deal with more short-term problems rather than focus on strategies in the short and medium term. Thus it could be said that SMEs tend to adopt a reactive more than a proactive attitude to changes in the environment. 
In relation to technological change, the EIMS study (European Commission, 1996) points out that the traditional SME tends to deal with it as a contingency, something that appears suddenly and needs to be negotiated if it cannot be avoided, more than as an opportunity (Dankbaar, 1998). Today, after a technologically stable era, many of these companies face radical and rapid changes in their productive processes: digitalization, new systems of the production, etc. A more critical fact is the rejection of the managers of SMEs (and especially those in the South) to face the problems of technology in a proactive way. This fact has to be kept in mind by the Public agencies of Innovation when promoting Programs of technology transfer to the SMEs.

Equally, SMEs tend to value more the information coming from its own environment as the already mentioned EIMS study points out. Also it should be taken into account that not only technical information and knowledge can be a barrier to innovation. Again the EIMS studies point out that commercial technological information is a demand in the innovative process of the SME.

In parallel, these problems are more acute in certain territories (the intermediate regions) at a distance from the centers of information (mainly located in urban areas) or where the IT culture has not yet been extended.

The clustering strategy consists in the monitoring of the main economic agents of a territory with the purpose of facilitating them information about their optimum success alternatives.

These policies are harvesting excellent results in some of the most dynamic regions in the world, with an industrial district profile, when it has been applied to networks of SMEs: the Emilia Romagna in Italy, Scotland in UK, Arizona, the Silicon Valley, highway 128 in Boston, New Zealand, Catalonia and the Basque regions in Spain, Finland, etc.

The firms of these advanced clusters adopt coordinated strategic change decisions starting from the mutual knowledge of their possibilities. And, in function of them, carry out managerial cooperation activities when designing projects and carrying out developments, which due to their span could reach at individual level with difficulty, being SMEs.

For the above reasons, the development of specific tools is required to systematize the formulation of clustering strategies and to find the know-how which will empower the local systems of innovation and, with them, the decisive factors of the territorial competitiveness.

The recovery of the marshallian theory on industrial districts by Becattini (1987; 1989), starts from the parallelism of the polarized localization of SMEs, registered in Italy in the decades of the 70s and the $80 \mathrm{~s}$, and the industrial reality of the textile and metallurgists industrial districts existing in Great Britain in the XIX century. The direction that seems to take the technological change of the last half a decade, in the measure that facilitates the delocalization of the production and the quick transport of goods, seems to renovate the initial conditions foreseen by Alfred Marshall (1919) for sustaining industrial districts, facilitating the proliferation of small specialized companies that work jointly in well defined areas and with certain outputs in a market open to international competition.

The cluster approach derives from the model of Porter (1990), which tries to explain why some nations attain sustained higher levels of productivity. Here the relevant questions appear to be: a) which environmental factors at national or 
regional level propitiate the development of competitive industries at international level?; and (b) Which are the governing bodies best suited to activate these factors? Porter recurs here to his known diamond model.

The strategic school has brought an alternate view on the cluster structure view (Porter, 1990). According to this school of thought, firm performance will be dependent on its favorable position within the structural competitive forces (bargaining power, rivalry, barriers to entry, etc.). A second strategic school of thought (Dyer and Singh, 1998) has recurred to the resource-based view of the firm (Barney, 1991; Rumelt, 1984, Wernerfelt, 1984) to propose that firm competitive advantage may draw from inter organizational relationships: interfirm relationspecific assets, knowledge sharing routines, complementary resources and capabilities and effective governance. This theory links the cluster approach with technology absorption capacity and knowledge management. A third school of thought develops these concepts by adding certain elements: building the knowledge repository, the interfirm relationships such as firm leadership, and the global cluster connections.

\section{CONCLUSIONS}

An analysis regarding relations between Knowledge Management and both organizational and environmental context has been realized.

It has been shown that these two factors have a strong influence on the way knowledge is created, transferred and shared in the same company and across its boundaries.

It has been deduced that, for a correct Knowledge Management, new organizational models (virtual organizations) and special business ecosystems (like clusters) are necessary, overall in the SMES case.

\subsection{Acknowledgments}

This research has been developed in the framework of a Project funded by the Comisión Interministerial de Ciencia y Tecnología (CICYT) of the Spanish Government and it is titled "Integración de Procesos de Negocio, Gestión del Conocimiento y Herramientas de Ayuda a la Toma de Decisiones en la Cadena de Suministro de PYMES Industriales.” Ref. DPI2002-01755.

\section{REFERENCES}

1. Apostolou, D; Mentzas, G. and Maas, W. (2003). "Knowledge Networking in Extended Enterprise". ICE, 9th. Internacional Conference on Concurrent Engineering, Espoo, Finlandia

2. Appleyard, M. M. (1996) "How does knowledge flow? Interfirm patterns in the semiconductor industry". Strategic Management Journal (17:Winter), pp. 137-154

3. Bagnasco, A. (1977): Tre Italie: la problematica territoriale dello sviluppo economico italiano. Il Mulino, Bolonia.

4. Barney, J(1991), Firm resources and sustained competitive advantage, Journal of management, 17 (1), 99-120.

5. Becattini, G. (1987): L' unitá d' indagine / Mercato e forze locali: Il distretto industriale. Il Mulino. Bolonia. 
6. Benko, G. and Lipietz, A. (1994): Las regiones que ganan. Ed. Alfons el Magnànim.

7. Brusco, S. (1982): The Emilian model: Productive descentralisation and social integration. Rev. Cambridge Journal of Economics, 6.

8. Bresnen, M. and N. Marshall (2000). "Building partnerships: case studies of client-contractor collaboration in the UK construction industry." Construction Management and Economics 18: 819832.

9. Camagni, R. P. (1992): Development Scenarios and Policy Guidelines for the Lagging Regions in the 1990s. Regional Studies, v. 26 n.4.

10. Camarinha-Matos, L.M. (2002). "Collaborative Business Ecosystems and Virtual Enterprises". IFIP TC5 / WG 5.5. Third Working Conference on Infrastructures for Virtual Enterprises (PRO-VE'02). Kluwer Academic Publishers.

11. Ciborra, C.U. y Andreu, R. (2001). "Sharing knowledge across boundaries". Journal of Information Technology, 16: 73-81.

12. Cushman, M. (2001). Action research in the UK construction industry - the B-Hive Project. IFIP 8.2, Boisit USA.

13. Dankbaar, B., (1998), Technology Management in technology contingent SMEs. International Journal of technology Management, Vol. 15, Issues 1-2. p. 70.

14. Ding, H. B. and L. S. Peters (2000). "Inter-firm knowledge management practices for technology and new product development in discontinuous innovation." International Journal of Technology Management 20(5-8): 588-600.

15. Dyer, J.H. y Singh, H. (1998) The Relational View: Cooperative strategy and resources of inter organizational competitive advantage. Academy of Management Review, 23: 660-679.

16. Egbu, C. and K. Botterill (2001). "Knowledge Management and Intellectual Capital: Benefits for project based industries". CoBRA.

17. Grant, R.M. y Baden-Fuller, C. (1995). "A knowledge-based theory of inter-firm collaboration". Academy of Management Best Papers Proceedings: 17-21.

18. Grant, R.M. (2001). "Knowledge and Organization". Nonaka, I. y Teece, D.J. (eds) (2001): "Managing industrial knowledge: Creation, transfer and utilization. Sage, London.

19. Levina, N. (1999). "Knowledge and organizations literature review". Prepared for the Society for Organizacional Learning, Cambridge.

20. Levy, M., C. Loebbecke, et al. (2001). SMEs, Co-opetition and knowledge sharing: The IS role. Global Co-Operation in the New Millennium

21. Liebeskind, J. P., Oliver, A. L., Zucker, L., and Brewer, M. (1996) "Social networks, learning, and flexibility: Sourcing scientific knowledge in new biotechnology firms". Organization Science (7:4), pp. 428-443.

22. Nonaka, I.; Toyama, R. y Cono, N. (2000). "SECI, Ba and Leadership: a Unified Modelo f Dynamic Knowledge Creation". Long Range Planning, 33: 5-34.

23. Porter, M. E. (1990): The Competitive Advantage of Nations. Harvard Business Review. March April.

24. Porter, M.E. (1994): The role of location in competition. Rev. Journal of the Economics of Business, $\mathrm{n}^{\circ} 1-1$.

25. Powell, W. W., Koput, K. W., and Smith-Doerr, L. (1996). "Interorganizational collaboration and the locus of innovation: Networks of learning in biotechnology". Administrative Science Quarterly (41:1), pp. 116-145.

26. Powell, W. W. (1998). "Learning from collaboration: Knowledge and networks in the biotechnology and pharmaceutical industries". California Management Review (40:3), pp. 228-240.

27. Pyke, F., Sengenberger, W. (1990): Introduction. International Institute for Labour Studies, Ginebra.

28. Rumelt, R.P. (1984) The evaluation of business strategy, in Glueck, W.F., (ed) Business policy and strategic management, Mc Graw Hill, N.Y.

29. Sabel, Charles (1992): Studies Trust: Building New Forms of Cooperation in a Volatile Economy, in Industrial Districts and Local Economic Regeneration (Frank Pyke y Werner Sengenberger, comp.). Intern. Inst. for Labour Studies, Inter. Labour Office. Ginebra.

30. Scott, B.R. (1989), Competitiveness: Self Help for a Worsening Problem, Harvard Business Review, 67(4), 115-121

31. Sweeney, Gerald. (1987): Innovation, Entrepreneurs and Regional Developement. Pinter, Londres.

32. Teece, D.J. (2001). "Strategies for managing knowledge assets: The role of firm structure and industrial context". En Nonaka, I. y Teece, D.J. (ed.): Managing industrial knowledge: Creation, transfer and utilization: 315-329. Sage, London.

33. Wernerfelt, B. (1984), A resource based view of the firm, Strategic Management Journal, 5,2, p. 171178. 